\title{
PREVISÃO DO DIAGRAMA DE CARGA DE SUBESTAÇÕES DA REN UTILIZANDO REDES
}

\section{NEURONAIS}

\section{Resumo}

A previsão de diagramas de carga é bastante utilizada por diversas empresas que lidam com o setor elétrico, o que torna este processo muito importante para a eficiência $e$ qualidade. As Redes Neuronais Artificias (RNA) são uma técnica computacional com diversas áreas de aplicação, sendo uma delas a previsão de cargas.

Ao longo deste artigo está presente todo o processo realizado para alcançar as redes ideais de duas subestações da Rede Elétrica Nacional (REN), Prelada e Ermesinde, e posteriormente desenvolver um método de previsão eficaz para diagramas de carga e comprovar que a utilização de RNA são uma mais-valia no alcance de boas previsões.

\section{Introdução}

Atualmente a energia elétrica desempenha um papel fundamental, tanto a nível económico do país, como a nível de conforto e satisfação individual.

Com o aumento dos produtores e a utilização de novas fontes primárias de energia os diagramas de carga têm sofrido modificações, devido ao carácter volátil de energias como o vento [1]. Deste modo, torna-se ainda mais importante o estudo de uma metodologia de previsão de diagramas de carga. Para tal, neste artigo utiliza-se as RNA, que são técnicas computacionais muito utilizadas em estudos de previsão, baseadas no funcionamento de uma rede neuronal biológica, e que têm como objetivo estimar valores de saída com base em vários dados de entrada.

\section{Redes neuronais artificiais}

As RNA são constituídas por muitas unidades de processamento, designadas por neurónios artificiais, que estão ligadas a canais de comunicação que se encontram associados a um determinado peso.
Os neurónios artificiais consideram as várias entradas possíveis, realizam o processamento da informação multiplicando o sinal recebido na entrada pelo peso, que indica a sua influência na saída, realiza de seguida a soma ponderada dos sinais que produz um determinado nível de atividade e por fim se esse nível exceder um certo limite a unidade produz uma resposta [1][2][3].

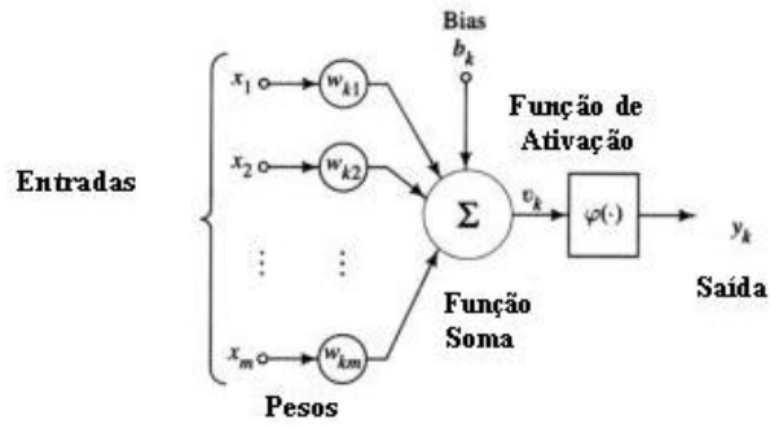

Figura 1. Modelo matemático utilizado pela RNA [3]

Um diagrama esquemático de uma RNA está presente na figura 2, geralmente a arquitetura destas redes é composta por uma camada de entrada, uma ou mais camadas ocultas, e uma camada de saída. Regra geral, cada neurónio é ligado aos outros neurónios da camada anterior através de pesos adaptáveis [3][4].

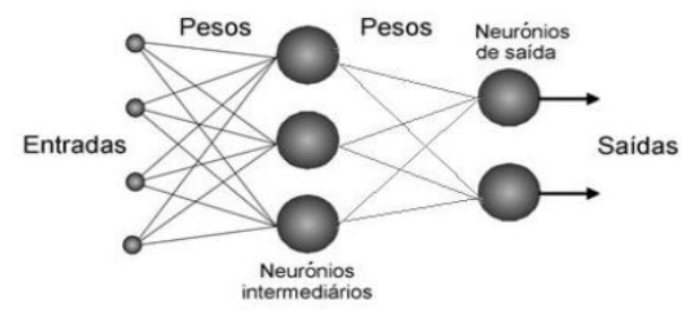

Figura 2. Esquema de uma RNA [2] 


\section{Método desenvolvido para a aplicação}

Para o desenvolvimento de uma rede neuronal utilizou-se a ferramenta Neural Network Fitting Tool, do MATLAB. Esta ferramenta resolve problemas de ajuste de input-output de uma rede neuronal feedforward de duas camadas, utilizando o algoritmo de Levenberg-Marquardt backpropagation.

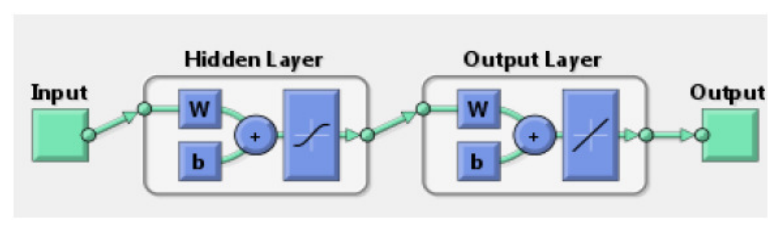

Figura 3. Esquema da arquitetura da $\mathbf{R N}$

A arquitetura das redes treinadas é composta por dados de entrada (Input), uma camada oculta (Hidden Layer), com neurónios ocultos ativados pela função tangente hiperbólica, uma camada de saída (Output Layer), com neurónios de saída ativados pela função linear, e finalmente pelos dados de saída (Output).

\section{Encontrar o melhor número de neurónios}

A primeira fase do método desenvolvido para alcançar a melhor rede, para o processo de previsão, passou por efetuar 5 treinos para cada um dos quatro conjuntos diferentes de neurónios, 10, 20, 25 e 30, que foram estipulados com o intuito de alargar o campo de opções para chegar a melhores resultados.

Através da ferramenta utilizada, no MATLAB, e analisando os dados obtidos no fim do processo de aprendizagem para os diferentes números de neurónios, a melhor rede obtida foi para 30 neurónios alcançando um erro médio quadrático de 6,94868 , no subconjunto do treino.

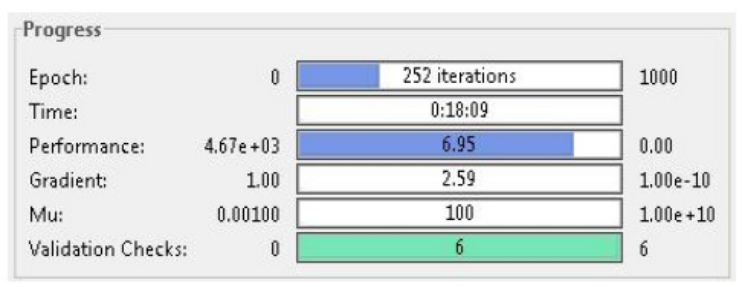

Figura 4. Progressos da melhor rede, com 30 neurónios

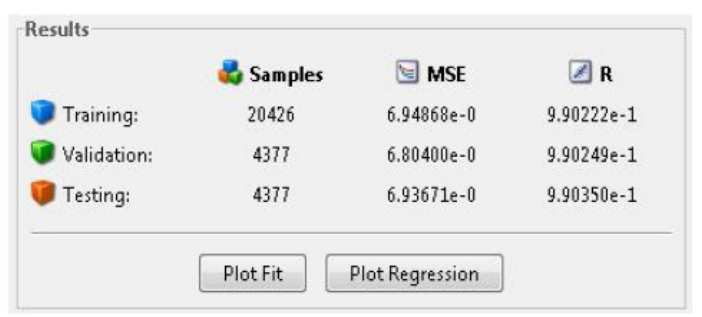

Figura 5. Resultados da melhor rede, com 30 neurónios

O treino terminou com um total de 252 iterações em 18min e 09s. Relativamente à melhor performance de validação, esta foi obtida na iteração 246, com um erro médio quadrático de 6,804.

\section{Encontrar a melhor percentagem}

Após obter o melhor número de neurónios a próxima fase passa por adquirir as melhores percentagens a utilizar em cada subconjunto (treino, validação e teste) da ferramenta.

Com a finalização de todos os treinos para os casos possíveis e a sua análise, verifica-se que a melhor opção de percentagens a utilizar é de $75 \%$ de Treino, $15 \%$ de Validação e $10 \%$ de Teste, tendo em consideração os resultados obtidos e o facto de subconjunto de Treino ser o mais relevante.

Impacto de diferentes conjuntos de dados na obtenção da rede ideal

Com a definição da estrutura e parâmetros da rede é possível passar à realização de treinos para alcançar a rede com os resultados mais favoráveis. Nesta fase é importante analisar que tipo de dados causam um maior impacto na aprendizagem da rede e assim verificar a importância que têm no treino.

Ao longo dos vários treinos e sua análise, para os diferentes conjuntos de dados (Temperatura, Humidade, Vento, Luminosidade e Feriados) é possível comprovar que dados como Feriados são essenciais, neste tipo de estudo, para alcançar melhores resultados. 
Têm um grande impacto na aprendizagem da rede, o que seria de esperar pois quando se trata de produção e/ou consumo de carga, neste tipo de dias, tem tendência a diminuir. No entanto, quando se utiliza todos os dados no mesmo treino é possível alcançar bons resultados, demonstrando que os dados em conjunto facilitam a aprendizagem e lhe permitem um maior conhecimento de comportamento passado.

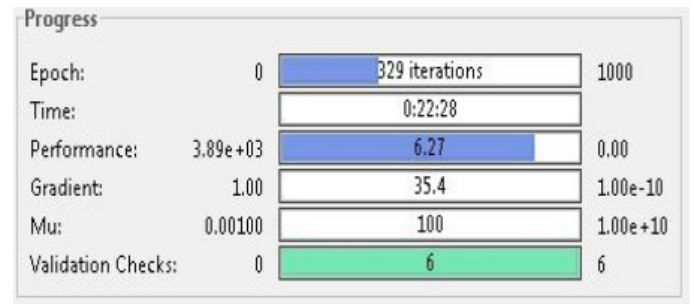

Figura 6. Progressos da melhor rede, com todos os dados, da subestação da Prelada

\begin{tabular}{lccc} 
Results & Samples & $\square$ MSE & $\square \mathbf{R}$ \\
Training: & 26280 & $6.26863 \mathrm{e}-0$ & $9.90823 \mathrm{e}-1$ \\
Validation: & 5256 & $6.19451 \mathrm{e}-0$ & $9.90918 \mathrm{e}-1$ \\
Testing: & 3504 & $6.23709 \mathrm{e}-0$ & $9.91100 \mathrm{e}-1$ \\
\hline & & & \\
\hline & Plot Fit & Plot Regression & \\
\hline
\end{tabular}

Figura 7. Resultados da melhor rede, com todos os dados, da subestação da Prelada

As figuras 6 e 7 demonstram os progressos e resultados obtidos na melhor rede encontrada, utilizando todos os dados disponibilizados pela REN, para a subestação da Prelada. A rede contém um erro de 6,26863 correspondente ao treino e um valor de regressão de 0,990823 para o mesmo subconjunto. A melhor performance obtida quanto à validação está presente na iteração 323 com um erro de 6,1945 .

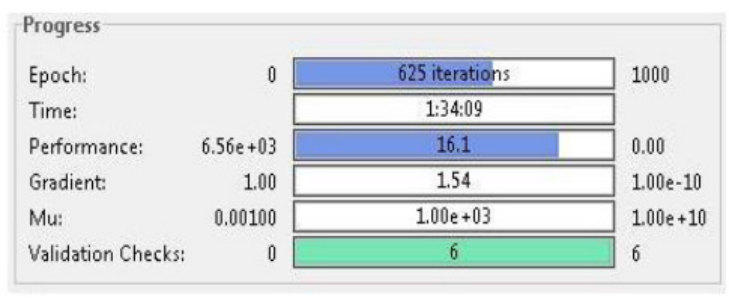

Figura 8 - Progressos da melhor rede, com todos os dados, da subestação de Ermesinde

\begin{tabular}{|c|c|c|c|}
\hline \multicolumn{4}{|l|}{ Results } \\
\hline & Samples & 包 MSE & $\triangle \mathrm{R}$ \\
\hline (1) Training: & 26280 & $16.09205 \mathrm{e}-0$ & $9.89925 \mathrm{e}-1$ \\
\hline (1) Validation: & 5256 & $17.10386 \mathrm{e}-0$ & $9.89378 \mathrm{e}-1$ \\
\hline \multirow[t]{2}{*}{ Testing: } & 3504 & $17.13372 \mathrm{e}-0$ & $9.89312 \mathrm{e}-1$ \\
\hline & Plot Fit & Plot Regression & \\
\hline
\end{tabular}

Figura 9. Resultados da melhor rede, com todos os dados, da subestação de Ermesinde

As figuras 8 e 9 demonstram os progressos e resultados da melhor rede obtida para a subestação de Ermesinde. Esta rede atingiu um erro médio quadrático de 16,09205 no subconjunto de treino, alcançando a sua melhor performance de validação na iteração 619 , com um erro de 17,1039 .

\section{Previsão do diagrama de carga}

A previsão dos diagramas de carga foi feita para dois dias e duas semanas, escolhidos aleatoriamente, do mês de Março de 2015, para as subestações da Prelada e de Ermesinde.

A realização da previsão consistiu em utilizar a melhor rede encontrada no processo de aprendizagem, através da ferramenta Neural Network Fitting Tool, para cada uma das subestações em análise, e o conjunto de Inputs, com todos os dados disponíveis correspondentes ao dia ou semana que se pretende efetuar a previsão, e utilizar a função criada para calcular saídas.

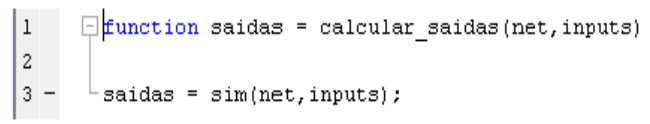

Figura 10. Função calcular saídas (Outputs)

Previsão de Diagrama de Carga do dia 18 de Março de 2015, da subestação da Prelada

Utilizando a função presente na figura 10 e a respetiva rede e Inputs, obteve-se o gráfico representado na figura 11. 


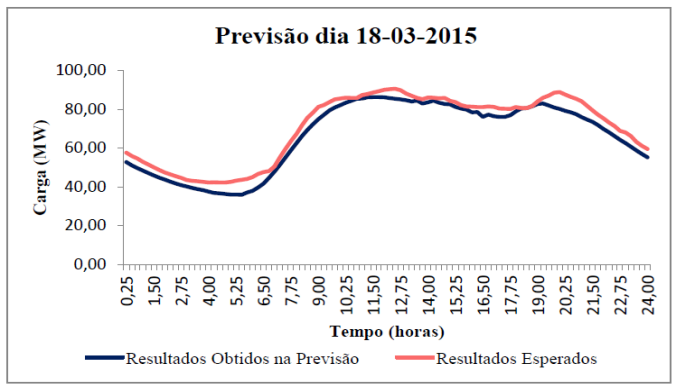

Figura 11. Gráfico de Previsão de Diagrama de Carga do dia 18 de Março de 2015

Através da análise da figura 11 verifica-se que os valores obtidos através da previsão são próximos dos valores reais, no entanto têm tendência a serem ligeiramente inferiores. Realizando a diferença entre os valores representados no gráfico de previsão obtém-se o erro existente entre eles que é, em média, 4,28, tendo uma variação entre 8,70 e 0,04.

\section{Previsão de Diagrama de Carga da 1a semana de Março de} 2015, da subestação da Prelada

Novamente utilizando a função presente na figura 10 e a respetiva rede e Inputs, obteve-se o seguinte gráfico.

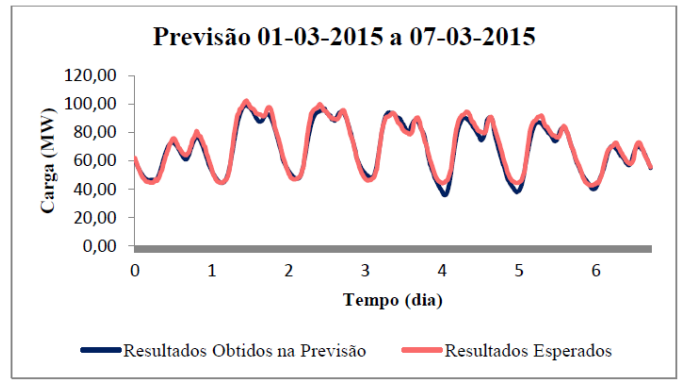

Figura 12. Gráfico de Previsão de Diagrama de Carga da 1a semana de Março de 2015

Analisando o gráfico é possível afirmar que a utilização de redes neuronais pode ser uma ajuda na previsão de diagramas de carga uma vez que os resultados obtidos são muito próximos dos resultados reais, no entanto deve ser tido em atenção o erro presente no processo de aprendizagem, que nunca chega a ser nulo e neste caso tem um valor de 2,49 (erro médio). A variação de erro ocorre entre os valores 9,88 e 0,01 .
Previsão de Diagrama de Carga do dia 30 de Março de 2015, da subestação de Ermesinde

Mais uma vez utilizando a função presente na figura 10 e a respetiva rede e Inputs, obteve-se o gráfico de previsão do dia 30 de Março, neste caso para a subestação de Ermesinde.

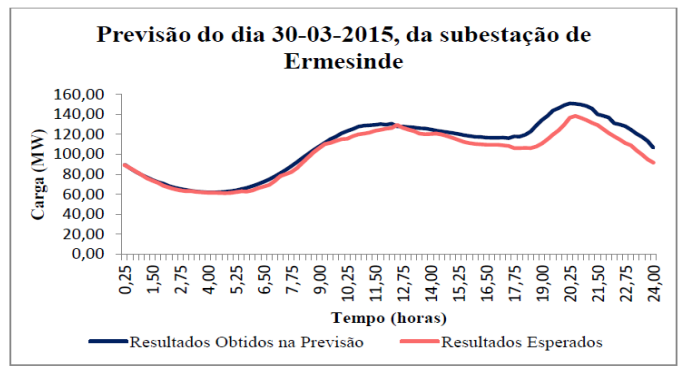

Figura 13. Gráfico de Previsão de Diagrama de Carga do dia 30 de Março de 2015

Pode-se verificar que os valores obtidos na previsão têm tendência a serem superiores aos valores esperados, contrariamente ao que acontecia na subestação da Prelada. Pode-se verificar ainda um aumento do erro entre os dois conjuntos de dados à medida que o tempo aumenta, principalmente a partir das $17 \mathrm{~h}$, aproximadamente. $\mathrm{O}$ erro médio atingido, neste dia, foi de 7,17, existindo uma variação entre um erro máximo de 24 e um mínimo de 0,01.

Previsão de Diagrama de Carga da 2a semana de Março de 2015, da subestação de Ermesinde

Através da função presente na figura 10 e a respetiva rede e Inputs, obteve-se o seguinte gráfico.

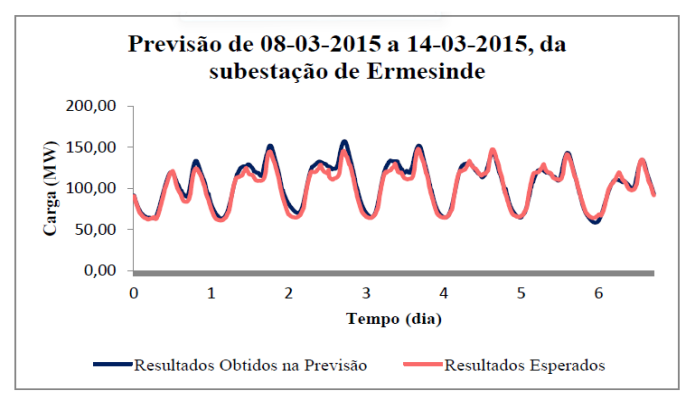

Figura 14. Gráfico de Previsão de Diagrama de Carga da 2a semana de Março de 2015 
Pode-se verificar que, mais uma vez, os valores alcançados na previsão tendem a ser ligeiramente superiores aos dados reais, no entanto seguem a linha dos resultados esperados. A variação do erro, nesta situação, ocorreu entre 19,75 e 0,005 o que calculou um erro médio de 5,01.

\section{Conclusões}

Analisando o comportamento dos dados obtidos nas previsões em comparação com os dados reais é possível concluir que as redes neuronais permitem obter previsões credíveis e satisfatórias. Conseguem seguir sempre a tendência do comportamento dos valores reais. No caso das previsões realizadas para a subestação da Prelada os valores obtidos têm tendência a serem inferiores aos valores reais, enquanto na subestação de Ermesinde acontece o oposto.

Quanto ao valor médio dos erros obtidos, no processo de previsão, são um pouco elevados, este valor devia ser mais próximo de zero e para que tal seria necessário aumentar o número de treinos realizados e utilizar dados meteorológicos próprios de cada localização, diminuindo as variações.

Pode-se concluir que as RNA são realmente um bom método para conseguir boas previsões. Na previsão de diagramas de carga pode ser uma mais-valia, pois é possível ter uma noção de qual ser o comportamento que a carga terá num determinado espaço de tempo e uma aproximação da quantidade de carga que será utilizada.

Para concluir este artigo, um especial agradecimento à REN e seus engenheiros, pelo apoio e disponibilização de dados que tornou possível a elaboração deste estudo.

\section{Referências}

[1] RODRIGUES, Ricardo. "Previsão dos consumos na RNT considerando a produção distribuída - Desenvolvimento de um procedimento de apoio à decisão do Gestor do sistema”. FEUP, 2014.

[2] BARROS, Tiago. "Previsão de carga - Comparação de técnicas". FEUP, 2014.

[3] HAYKIN, Simon. "Neural Networks - A comprehensive Foundation". 2a Edição. Pearson Education, Canadá, 1999.

[4] KALOGIROU, Soteris A.; BOJIC, Milorad. "Artificial neural networks for the prediction of the energy consumption of a passive solar building". Department of Mechanical and Marine Engineering, Higher Technical Institute, Cyprus, e University of Kragujevac, Faculty of Mechanical Engineering, Department of Energy and Process Engineering, Yugoslavia. Elsevier Science Ltd., 2000.

\section{Notas soltas:}

\begin{tabular}{|c|c|c|}
\hline Fator & Prefixo & Símbolo \\
\hline $10^{24}$ & yotta & Y \\
\hline $10^{21}$ & zetta & Z \\
\hline $10^{18}$ & exa & E \\
\hline $10^{15}$ & peta & P \\
\hline $10^{12}$ & tera & T \\
\hline $10^{9}$ & giga & G \\
\hline $10^{6}$ & mega & M \\
\hline $10^{3}$ & kilo & K \\
\hline $10^{2}$ & hecto & h \\
\hline $10^{1}$ & deca & da \\
\hline
\end{tabular}

\begin{tabular}{|c|c|c|}
\hline Fator & Prefixo & Símbolo \\
\hline $10^{-1}$ & deci & d \\
\hline $10^{-2}$ & centi & c \\
\hline $10^{-3}$ & mili & m \\
\hline $10^{-6}$ & micro & $\mu$ \\
\hline $10^{-9}$ & nano & $\mathrm{n}$ \\
\hline $10^{-12}$ & pico & $\mathrm{p}$ \\
\hline $10^{-15}$ & femto & $\mathrm{f}$ \\
\hline $10^{-18}$ & atto & $\mathrm{a}$ \\
\hline $10^{-21}$ & zepto & $\mathrm{z}$ \\
\hline $10^{-24}$ & yocto & $\mathrm{y}$ \\
\hline
\end{tabular}

